\title{
La transmisión de los proverbios atribuidos a Menandro en el monaquismo eslavo medieval
}

\author{
Patricia GonZÁlez Almarcha \\ Universidad Complutense de Madrid \\ patukina@gmail.com
}

Recibido: Mayo de 2012

Aceptado: Diciembre de 2012

\begin{abstract}
Resumen
Mientras que la obra cómica se preserva exiguamente durante largo tiempo, los proverbios atribuidos a Menandro sobreviven desde temprano en colecciones compiladas en el Imperio bizantino y traducidas a diversas lenguas antiguas, entre las que se cifra el eslavo eclesiástico. Las técnicas que empleaban los traductores eslavos para reflejar las unidades morfológicas, léxicas y sintácticas griegas y, en especial, el contenido filosófico (incluso pagano), permiten alcanzar una comprensión más profunda del contacto cultural bizantino eslavo y muestran la praxis de traducción de los eslavos y su cosmovisión (ideología) en una atmósfera más moral que ético-filosófica, monacal que laica.
\end{abstract}

Palabras clave: literatura proverbial, antiguo eslavo, Bizancio, monaquismo, colación

The Transmission of Attributed to Menander Proverbs in Medieval Slavic Monasticism

\begin{abstract}
While the plays themselves are poorly preserved, proverbs attributed to Menander survived in collections compiled in the Byzantine Empire and subsequently translated into various old languages, including Old Church Slavonic. The techniques used bythe Slavic translator(s) to render Greek morphological, lexical and syntactical units and, in particular, philosophical (even pagan) content, allow a deeper understanding of Byzantine-Slavic cultural contact, being good illustrations of the challenging task of grasping the translational praxis of medieval Slavic bookmen-churchmen and an excellent tool for tracing their world-view (ideology) in a moral rather than ethical atmosphere, and in a monastic rather than laic arena.
\end{abstract}

Key words: Wisdom literature, Old Church Slavonic, Byzantium, monasticism, collatio

La traducción eslava de las sentencias de Menandro se enmarca dentro del fenómeno de transferencia de la cultura clásica (profusamente investigado en THOMSON 1999) en la Commonwealth Bizantina (atendida con eficacia en FRANKLIN 2002). Una descripción pormenorizada de las ediciones y de los manuscritos grecoeslavos preservados nos lleva a acotar la cuestión crítico-textual (БУСЛАЕВ 1861, МЕЩЕРСКИЙ 1978, GORSКIJ 1964 a y b). Una vez reunido el material proverbial, abordamos los problemas de traducción de la fuente griega al antiguo eslavo, 
emanados de una serie de peculiaridades que harán el texto menandreo distinto según se haya copiado desde parámetros ético-filosóficos o morales, con fines teóricos o prácticos, confrontando lo particular con lo universal, lo concreto con lo abstracto... Se trata en efecto, de poner la palabra en su contexto, para medir hasta qué punto unos universales aplicables como normas generales, unas observaciones eruditas sobre la vida, funcionan como tales al trasponerse a la órbita de la Iglesia eslavo ortodoxa medieval. La antología de los proverbios greco-bizantinos, al traducirse al eslavo eclesiástico, se convierte en una guía de buena conducta cristiana, en especial monástica, por lo que evoluciona de lo mayoritariamente teórico a lo eminentemente práctico. Puesto que el formato de 'sentencia' carece de entorno, se vuelve más abstracto o indefinido (inherente al género proverbial, como en KRIKMANN 1974 se describe por doquier), en contraposición a las comedias de Menandro, donde las máximas se ponen en boca de los personajes como exempla. De ahí la lógica de la universalización de un Menandro que fuera quizá más particular. En su tránsito del clasicismo a la "eslavidad", atravesando por el bizantinismo, el Menandro Ático y Filósofo muta en un Sabio Menandro, disfrazado del Prudente Salomón responsable del Libro de los Proverbios (un estudio pormenorizado de este capítulo bíblico de repercusión ingente en la incorporación de las sentencias menandreas a la tradición cultural eslava medieval se ofrece en TOY 1908).

Los monjes eslavos que desde el siglo XII tardío (con la evangelización cristiana ya muy avanzada) se afanaron en incorporar los florilegios menandreos a la tradición cultural eslava medieval, reproducían total o parcialmente los textos que les llegaban en códices misceláneos segmentados ${ }^{1}$, amenizándolos con algún que otro excurso, colofón o reinterpretación, propaganda intencionada o descuidos accidentales, pero siempre testificando, consciente o inconscientemente, una autoridad determinada y específica como rúbrica fundamental de esa parte del manuscrito adeudada, o al menos incluyendo un título aglutinante (Мена(н)дра Ноуараго о Поученнюе фйофна $)^{2}$ del fragmento textual copiado como línea fronteriza entre los distintos materiales de un mismo códice o pergamino. Algunos de estos proverbios eslavos no se incluyen en los códices bizantinos, sino que se hallan sin más en los papiros. Esto significa que en un buen número de casos los textos proverbiales eslavos remontan sus orígenes a una fuente griega más antigua aún que la atestiguada por el filólogo griego. En todo caso, el testigo de la distribución de los proverbios en un contexto diferente al greco-bizantino y para otras finalidades distintas a la erudición.

Los ejemplares manuscritos de las sentencias eslavas ya no se destinarían a la misión edificatoria en el púlpito (a juzgar por la datación de los códices eslavos más tempranos en virtud de los datos lingüísticos que arrojan). Se consagraban por aquellas alturas al uso privado monástico o principesco, con el fin del bien cultural común de Bizancio o, en este caso, religioso y espiritual de la Slavia Orthodoxa. En Medioevo eslavo, Menandro no era percibido como pagano, sino como un sabio

\footnotetext{
${ }^{1}$ En EDMONDS (1961) se ilustra muy bien la peculiaridad de la transmisión inicial de las máximas menandreas como extractos de la obra cómica autorial.

${ }^{2}$ Así en Sc: manuscrito ruso, siglo XVI, Monasterio Trinitario de San Sergio no. 730; fotografías disponibles en la red (http://www.lavra.ru/manuscripts.medium.php?col=1\&manuscript730; comentado por JAGIĆ (1892a: 10-19), y (1892b: 7-8).
} 
judeo-cristiano en la línea del Rey Salomón, cuyas duchas palabras podrían utilizarse en la construcción ortodoxa de monjes mejores, de príncipes más capaces. Además, la transmisión fragmentaria de las compilaciones gnómicas asignadas a Menandro que perviven en reproducciones manuscritas complejas, en el entorno de otras muestras escritas de índole diversa (proverbios salomónicos, consejos de magia y superchería popular, vidas de santos ascetas o discursos patrísticos de San Juan Crisóstomo) da cuenta de cómo los traductores antiguo eslavos van adaptando los florilegios de un politeísmo pagano o de un clasicismo erudito al cristianismo eslavo ortodoxo, más exiguo en el remanente clásico tradicional, pero profusamente salpicado de otras pintorescas creencias nuevas ${ }^{3}$.

Y para muestra de los múltiples mecanismos lingüísticos e ideológicos de transformación de las colecciones sentenciosas aunadas, basten algunos ejemplos rescatados del corpus de florilegios preservado en antiguo eslavo de recensiones serbia y rusa (JAGIĆ 1892a: 1-19 y b:1-103, CEMEHOB 1892: 1-42, FÜHRER 1982, MORANI 1996), en cotejo con la fuente griega autorizada (JÄKEL 1964). Las ilustraciones escogidas se agrupan semánticamente en virtud de la clasificación por conceptos clave (aquellos que son representativos de una cultura determinada, frecuentes y relevantes en ámbitos específicos de las civilizaciones distintas y que operan un punto bisagra en la transferencia y el entendimiento interculturales, WIERZBICKA 1997).

¿Cuáles son, así pues, los aspectos más significativos o relevantes del paganismo menandreo, de la erudición bizantina, que la Slavia Orthodoxa rescata y renombra para el beneficio del monaquismo, en especial, y de la edificación secular, en última instancia? El amor al prójimo constituye uno de los mandamientos fundamentales para el fiel cristiano. Los copistas antiguo eslavos lo retocarán en el proverbio que sigue de una manera muy sutil:

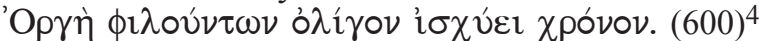

La ira de los que aman tiene fuerza durante poco tiempo ${ }^{5}$.

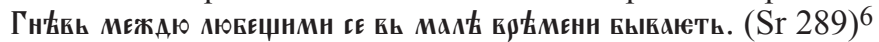

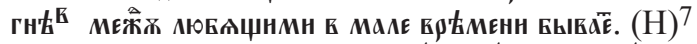

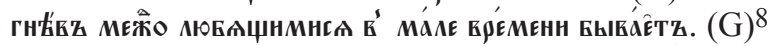

La ira entre los que se aman dura poco tiempo 9 .

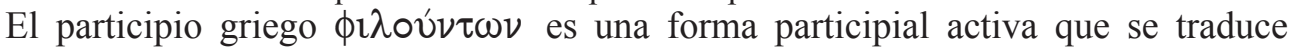
como: "aquellos que aman (a los otros)". Este participio activo, cuya sintaxis explora concienzudamente VEČERKA (1961), está en correspondencia plena con la

\footnotetext{
3 Para los distintos "convoy", v. GONZÁLEZ ALMARCHA (2010: 719-722).

${ }^{4}$ Las versiones griegas de los proverbios citados en este artículo proceden, salvo que se indique algo diferente, de la edición de JÄKEL (1964)

${ }^{5}$ Las traducciones españolas de los proverbios griegos citados en este artículo se toman, a menos que sea anotado de otra manera, del trabajo de MARIÑO (1999)

${ }^{6} \mathrm{Sr}$ : manuscrito serbio, siglo XIV, conocido originariamente de la Biblioteca privada de Panta Srećković, sito ahora en la Biblioteca Nacional de Belgrado, Serbia; disponible en edición diplomática numerada por JAGIĆ (1892 a: 25), y (1892 b: 8-9).

7 H: manuscrito ruso, siglo XVI, Biblioteca Sinodal de Moscú no. 323; disponible en edición diplomática numerada (SEMENOV 1892: 19-22); JAGIĆ (1892b: 6-7).

${ }^{8}$ G: manuscrito ruso, siglo XVI, Archivo del Ministerio de Asuntos Exteriores de Moscú no. 658-1170; disponible en edición diplomática no numerada (SEMENOV 1892: 23-33).

${ }^{9}$ Las traducciones castellanas de las redacciones proverbiales eslavas son propuesta, siempre mejorable, de la autora del presente artículo.
} 
copia de origen ruso H (АюБАцннмн), si bien мєжิт introduce hasta cierto punto una idea de reciprocidad (ABAHECOB 1990). Dicho significado recíproco se explicita en el verbo reflexivo de la redacción serbia Sr y del manuscrito ruso G (Аюбєцнмн ѓ июБАцннмнг (A): "los que se aman unos a otros". ¿Obedece tal reciprocidad a una asociación con los dichos cristianos en torno al amor al prójimo?

Además de la base amorosa, el cristianismo se erige sobre el pilar del verbo. Esta virtud "logocéntrica" heredada del democratismo griego también atraviesa sus transformaciones al pasar por el tamiz eslavo ortodoxo:

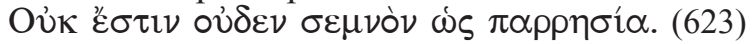

Nada es tan respetable como la libertad de palabra.

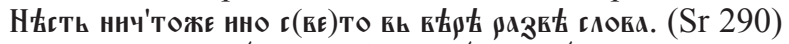

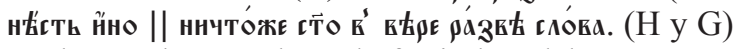

No hay nada sagrado en la fe sin la palabra.

Esta vez el traductor eslavo se aparta del modelo griego con una cristianización bastante libre. En primer lugar, escoge $\mathbf{г}(\mathbf{k})$ то como equivalente del griego $\sigma \varepsilon \mu \nu$ ò (que puede tener el significado de 'sagrado', LAMPE (1968: s.u.), pero que equivale habitualmente a 'honorable', 'honroso' o similares, LIDDELL y SCOTT (1996 : s.u.); después reinterpreta $\pi \alpha \rho p \eta \sigma i ́ \alpha$ en слока, 'la Palabra (de Dios)' (incluso a pesar de que el equivalente exacto Арұз̆нокєннє esté perfectamente atestiguado en el contexto cristiano: ЦЕЙТЛИН 1999: s.u.); por último, añade el elemento acla-

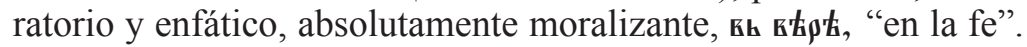

Con todo, si no quisiéramos tildar al escriba de adaptador con una voluntad ideológica obvia, siempre podemos recurrir a una explicación lingüística (ciertamente más complicada que el simple maquillaje moral recién explicado). El copista habría redividido la unidad léxica $\pi \alpha \rho \rho \eta \sigma i ́ \alpha$ en la construcción hipotética $\pi \alpha \rho$ ' $\rho \eta$

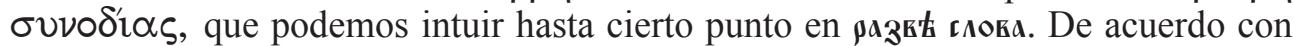
ИСТРИНЪ (1922: s.u.), разв' se corresponde con el griego $\pi \alpha \rho \alpha$, 'sin' en algunos ámbitos de la traducción de la Crónica de Amartolos. El griego ṕ se traduciría por el infinitivo 'hablar', en función sustantiva. Si la preposición griega $\pi \alpha \rho \alpha$ puede regir genitivo, la palabra $\sigma v v o \delta i \alpha \varsigma$, 'compañía', habría sido forzosamente derivada (en la escritura libre o al dictado) de una hipotética abreviatura en $\sigma^{\prime} t \alpha$. De este modo, el escriba habría escrito o escuchado : $\pi \alpha \rho$ ' $\rho \eta \sigma^{\prime} \imath \alpha$, reanalizando en el sintagma preposicional "sin la compañía del hablar", estructura que podemos rastrear

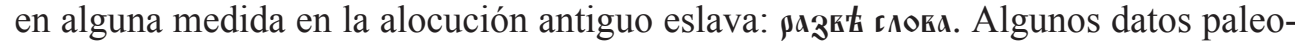
gráficos genéricos que podrían convenir a este tipo de especulaciones hallamos en КАРСКИЙ (1928). De cualquier manera, faltaría la explicación meramente lingüís-

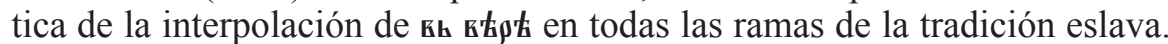

Si la vida monástica se percibe como la encarnación del ideal cristiano en la tierra, en el monasterio donde los monjes habitan en amorosa fraternidad y actualizan la sacrosanta palabra de Dios con la oración, hay otros votos imprescindibles conducentes a una exaltación del asceta por excelencia: la sobriedad etílica, como componente irrevocable del plan virtuoso de renuncia de muchas escuelas monacales que dan semillero ideológico a la utilización del Menandro griego por parte de los transcriptores eslavos: 


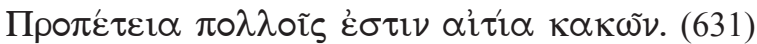

La precipitación es para muchos causa de males.

Каранніе мноз'мь внна бықають з'моу. (Sr 294)

La preocupación (es) para muchos causa del mal.

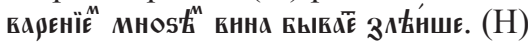

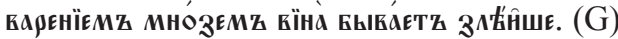

La anticipación suele ser para muchos causa de mal mayor.

El lexema караннıе (preocupación-ocupación monástica) parece ser un error gestado

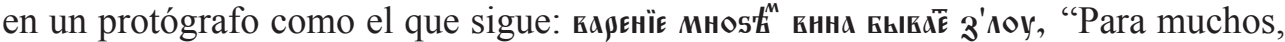
la anticipación (варєнїє traduce al griego $\pi \rho о \pi \varepsilon \tau \varepsilon 1 \alpha$, 'precipitación') es la causa (внна en su significado más antiguo según MIKLOSICH 1886: s.u.) del mal”. En los manuscritos $\mathrm{H}$ y $\mathrm{G}$ también se habría alterado la lectura del protógrafo; el antiguo eslavo варєнїв se convierte en варєнївмz por contaminación del caso de la palabra anterior. Esta innovación podemos interpretarla como un nuevo análisis del dativo plural en instrumental singular. A partir de aquí, no le queda al escriba un sujeto posible salvo внна (que fuera predicado); з'коу se convierte entonces en un comparativo en un esfuerzo último de darle sentido a una frase oscura: "Una falta se vuelve peor por la mucha precipitación". En última instancia, podemos rehelenizar el proverbio resultante de $\mathrm{H}$ y $\mathrm{G}$ en una propuesta de traducción más próxima al griego, aunque virtualmente más libre con respecto a una sintaxis propiamente antiguo eslava: "La anticipación suele ser para muchos causa de mal mayor". Desde el punto de vista ideológico las tres variantes eslavas nos remitirían a una suerte de ideario monástico tendente a la inacción o a la falta de actividad mundana, a favor de la práctica espiritual.

Al igual que la verdad para un ser debido a sus votos reside en la existencia contemplativa, tranquila, sopesada, la calumnia o la mentira quedan totalmente fuera del proyecto cristiano dentro de una orden como reducto último y más perfecto de la comunidad en Cristo:

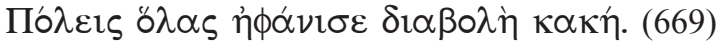

Una calumnia malévola ha destruido ciudades enteras.

Грааы в'сє погоувіть гваАа з'яа. (Sr 309)

Una calumnia malévola destruirá todas las ciudades.

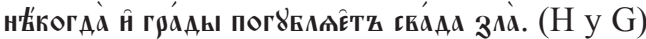

A veces una calumnia malévola destruye incluso ciudades.

En este bloque proverbial hay tiempos verbales diferentes en la fuente griega y en las versiones eslavas; la variación no afecta en gran medida al significado, si bien

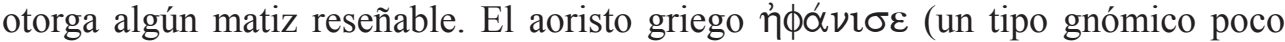
habitual para las afirmaciones generales, función que suele desempeñar el pasado con aumento) es una observación de lo que ha ocurrido: 'ha destruido'; el lector debe inferir de ahí que algo similar puede suceder en el futuro. El manuscrito Sr vierte el aoristo con un futuro que evidencia el porvenir: погоукіть. Puesto que se trata de un consejo, parece más apropiado al escriba expresarlo en futuribles (lo que ocurrirá: destruirá) que con un pasado (lo ya sucedido: ha destruido). El texto de redacción rusa utiliza un presente (погУБлАе́̂тт), para indicar una verdad general: en ocasiones 
sucede ('destruye') ${ }^{10}$. Además omite el pronombre k'cє, lo que podemos atribuir quizás a la ambigüedad que implica: 'ciudades enteras' o 'todas las ciudades' (donde la última posibilidad entrañaría una interpretación errónea del original griego, que desemboca en la supresión pronominal). La interpolación del participio enfático н refuerza la hipótesis de una vacilación en la sintaxis pronominal.

El antibelicismo y la resistencia pacífica como eslabones insalvables de la doctrina cristiana también se contemplan desde un prisma ligeramente disímil en el ámbito eslavo ortodoxo:

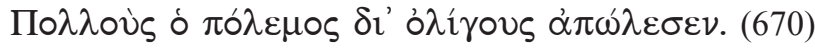

La guerra destruye a muchos por causa de pocos.

Н'ногы рать вьскорь погоувнть. (Sr 310)

La guerra destruye a muchos en poco.

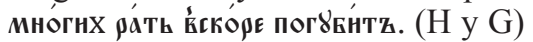

La guerra destruye a muchos en poco.

Así la discusión sobre los problemas de traducción que puede entrañar esta sentencia y que dejan asomar ciertas tendencias ideológicas se arraciman en torno al sintagma griego $\delta i^{\prime}$ ó $\lambda$ írovs. Podemos pensar que el antiguo eslavo кьгкорł es un intento fallido de trasladar el griego en cuestión, de manera que el escriba ha mantenido su posición sintáctica sin entender que $\delta \imath^{\prime}$ b $\lambda$ íyovs puede referirse tanto a los agentes como a los beneficiarios de la acción; entonces toma la idea de lo 'poco' y la transpone al campo semántico del tiempo. Notamos de nuevo el cambio del aoristo (con reflejo en la historia de la que el lector o receptor deberá extraer lecciones) a un futuro (los problemas potenciales a prevenir mediante el buen comportamiento presente). Con todo, también se puede interpretar que el traductor eslavo no ha vertido $\delta \mathrm{l}^{\prime}$ ó $\lambda$ í $\gamma o v s$ intencionalmente, pues la guerra resulta un ámbito poco cristiano o ajeno a la religiosidad. El hincapié eslavo ortodoxo está en que la guerra mata y lo hace rápidamente, sin importar a causa de quién o de qué. Los oligarcas enfrentados en el plano terrenal, los políticos mundanos, no le interesan al monje eslavo. En el compendio literario denominado Izbornik de $1076^{11}$ se recoge el desinterés expreso hacia los paganos, los griegos, que podría tener cierta cadencia en una posible omisión voluntaria como la recién planteada.

La paz que deja y da la divinidad a los cristianos, ritualizada en la celebración de la eucaristía, nos parece contenido y continente último de un verso como el precedente; no menos trascendente que la oración dicha, pronunciada en palabras que desean y esperan:

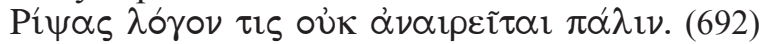

Cuando se ha lanzado una palabra, no se recoge de nuevo.

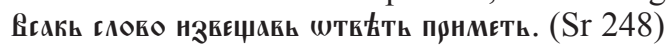

Cada palabra dicha obtiene una respuesta.

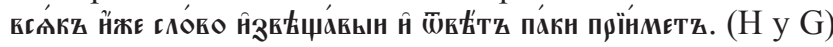

Todo el que ha dicho una palabra, obtiene además una respuesta.

Hay pasajes famosos del Sermón en el Monte (por ejemplo, Mateo 7,8, Lucas 11,10) que encierran una estructura gramatical similar a las redacciones eslavas de este pro-

\footnotetext{
${ }^{10}$ Sobre la variación aspectual tenemos que considerar sin duda el concienzudo examen de DOSTÁL (1954).

11 Muchos son los estudiosos que se ocupan de esta compilación edificante; nosotros traemos a colación la referencia de VEDER (1994).
} 


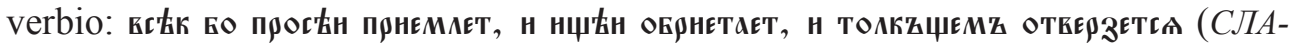
ВЯНСКАЯ БИБЛИЯ ДЛЯ WINDOWS 2002). El pensamiento que se desgaja de las sentencias de la tradición eslava es el de que si alguien pide en oración, recibirá una respuesta de Dios. Sin embargo, el texto griego sostiene algo ligeramente diferente; tiene que ver con el tema de la discreción, de no decir cosas fuera de lugar: "alguien que ha lanzado una palabra, no la revocará". Hay, en efecto, proverbios que afirman esta idea en las lenguas eslavas, algunos de ellos evidentemente antiguos, pues son compartidos. De todos modos, esta vez el traductor convierte el consejo griego de reprimir la lengua en una lección sobre la oración; de ahí que se desprenda del negativo ou ${ }^{1} \mathrm{k}$ y de la evaluación negativa contenida en pí $\psi \alpha S$ (frente a un neutral нззьћцатн), у refuerza la idea de recibir una respuesta en un lenguaje neutral. Se puede, por supuesto, interpretar el antiguo eslavo en la línea del griego: "si dices algo (es decir, descuidadamente), obtendrás una respuesta (o sea, malas consecuencias)". De cualquier forma, esta hipótesis exige bastante profundización en el contexto, por lo que resulta probablemente mejor asumir que el traductor está innovando, ora accidental, ora deliberadamente, por razones ideológicas.

El rezo como súplica interior o comunitaria, como actualización práctica de un verbo divino, se abre camino hacia el aspecto exegético de una de las religiones del libro, donde la retórica y el arte oratorio clásicos, se reconducen en el sermón y en la prédica de las Escrituras dentro del cristianismo, en la puesta en práctica de los libros sagrados dentro del monaquismo:

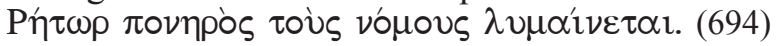

Un orador malvado ultraja a las leyes.

Свъть моукакь слокеса раскажають. (Sr 256)

El consejomalvado estropea las palabras.

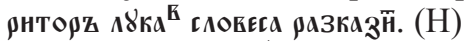

рнторь $\Lambda 8 к а^{\mathrm{K}}$ слокеса расказнтъ. (G)

El orador malvado estropea las palabras.

Presumiblemente los proverbios rusos $\mathrm{H}$ y $\mathrm{G}$ reflejan una versión más primitiva que $\mathrm{Sr}$, puesto que escriben texto originario recogiera la variante ск'тьь, no existiría modo de que рнторь pudiera haber sido sustituido, a menos que el editor eslavo tuviera el manuscrito griego ante sí. Si hubiera partido de una redacción con ск'冖ть podría haber propuesto una desviación en гъвфтннкъ о similar. Entonces el serbio preservado свћть podría leerse como un error a partir de гъкътннкъ о podría considerarse una sustitución metonímica (el consejo por el consejero, la acción en lugar del agente). La metonimia serviría para despersonalizar y generalizar el contenido. Contrariamente, blemente fuera para el copista eslavo una institución exótica, de modo que un monóstico que incluyese un término de tal índole tendría escaso valor social.

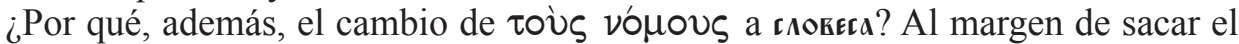
sentido general del proverbio de una esfera cívico-legal (la arena propia del retor antiguo griego, pero irrelevante para los monjes eslavos), la sustitución parece ser cristianizante. Las leyes vómol se identifican con las Escrituras, un significado que llega a la lengua griega a través del cristianismo, por influjo de la idea hebrea de la Ley. La unidad léxica гловєєа indicaría sin duda las palabras de las Escrituras en esla- 
vo eclesiástico. De hecho se percibe en el griego una intencionalidad de ruptura de la ley, que en antiguo eslavo supondría una desviación en el análisis del significado de las Sagradas Escrituras o una profanación de las mismas (ámbito moral). Se trata de un alejamiento de la moral más que del civismo. Así pues, lo que fuera una afirmación sobre la ley en el texto griego, se convierte en una sentencia sobre la religión en antiguo eslavo.

Los dictados legales emanados de la Biblia parten de la razón como fundamento óptimo que construye el cristianismo, una fe racional; la sabiduría menandrea, la percepción del comediógrafo ateniense como autoridad judeo-cristiana, reconvierte el paganismo de la endiosada razón en dogmas demostrados contra la apostasía, de ahí que los traductores proverbiales eslavos atiendan a la inteligencia de los sabios desde puntos de mira muy particulares:

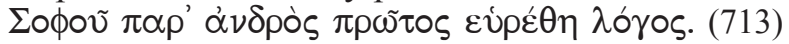

En un hombre sabio lo primero que se descubre es la razón.

OУ моуара моужа шер'тте ге прьвоюе Хнтрогть. (Sr 268)

En un hombre sabio lo primero que se descubre es la razón.

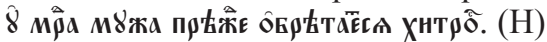

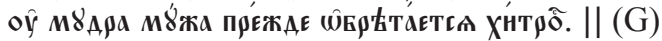

En un hombre sabio ante todo se descubre la razón.

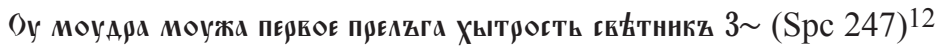

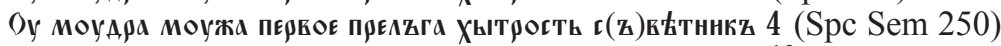

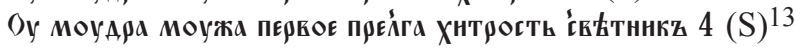

La astucia de los consejeros ha engañado, para empezar, incluso a un hombre sabio.

La primera redacción eslava ( $\mathrm{Sr}$ ) carece de implicaciones negativas. Las diferencias con respecto a las recensiones rusas radican en el orden de palabras y en la uti-

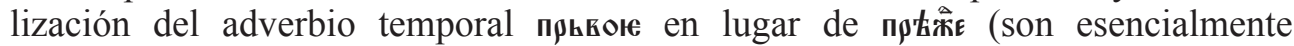
sinónimos, ЦЕЙТЛИН 1999: s.u.). Así, podemos leer: "En un hombre sabio lo primero que se descubre (y sobre todo) es la razón/destreza/astucia o agudeza". Las versiones eslavas preservadas en Spc y en S son claramente secundarias y derivan del texto con прьвою. Parece que las posibles asociaciones negativas que despertaría la palabra ұытрогть (que en los escritos cristianos se vincula con el diablo y con el engaño) habría llevado al editor a explicitar la idea del engaño en прєаzга que sustituye al semánticamente vacío wิEpłtietra. Ahora bien, ¿por qué el aoristo? Quizás este tiempo de pasado haya sido motivado por el adverbio прькою, pues "primeramente" sugiere una suerte de ordenación temporal. De todos modos, restaría por resolver quién es el engañado y por quién está siendo engañado; pensamos que el "hombre sabio" podría ser el objeto nocional con la vieja construcción preposicional conservada del texto de partida (o incluso alguna resistencia a cambiar la primera palabra de la sentencia). Así, ск'ттннкъ se habría añadido para hacer explícito el agente (LUNT 1974 resulta una referencia práctica para cuestiones gramaticales eslavo-eclesiásticas): "La astucia de los consejeros ha engañado en primer lugar

\footnotetext{
12 Spc: manuscrito ruso, siglo XIV, Biblioteca Pública de San Petersburgo no. I, 44; disponible en edición diplomática numerada (JAGIĆ 1892b: 75-103). Semenov publica una versión ligeramente distinta, con ciertas regularizaciones paleográficas y ortográficas, del mismo manuscrito (Spc Sem) (1892: 5-17).

${ }^{13}$ S: manuscrito ruso, siglo XVI, Biblioteca Sinodal de Moscú no. 324; disponible en edición diplomática no numerada (SEMENOV 1892: 4-17).
} 
(incluso) a un hombre sabio". También puede plantearse otra lectura que no implique asumir errores gramaticales: "El consejero ha engañado en primer lugar la astu-

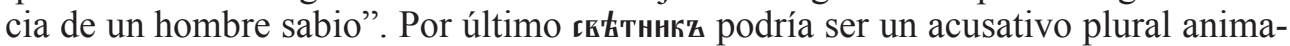
do, de modo que obtendríamos: "Con un hombre sabio, la astucia ha engañado primero a los consejeros". Quizás las dos últimas lecturas, libres de fallos gramaticales, sean las más procedentes. Desde la perspectiva ideológica, podríamos interpretar que el contenido textual hace referencia al poder del sofista de engañar incluso al más sabio, un análisis que entraría en consonancia con otros proverbios de la antología atribuida a Menandro:

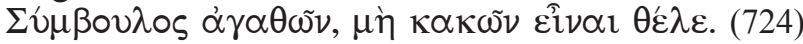

Desea dar buenos consejos, no malos.

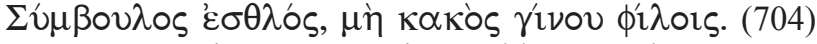

Sé para tus amigos un consejero noble, no malo.

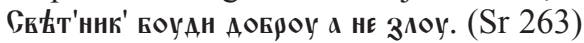

Sé un consejero bueno, y no malo.

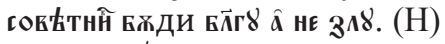

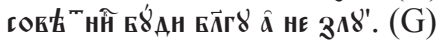

Sé un consejero excelente, y no malo.

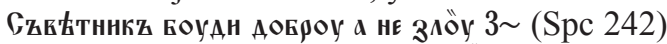

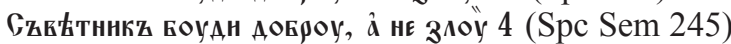

Sé un consejero bueno, y no malo.

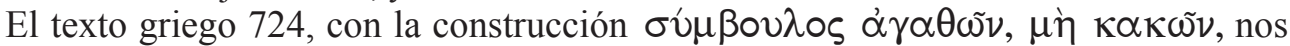
parece un tanto ambiguo, pues de él pueden inferirse dos variantes de lectura: "Sé un consejero de buenas personas/de buenas cosas". Puesto que la lengua griega tiende a utilizar más el número plural para los genéricos que el antiguo eslavo, el sintagma singular eslavo eclesiástico АоБроу a HE $\mathbf{3}^{\text {noy }}$ puede desembocar en una interpretación del tipo: "Sé un consejero del bien, no del mal" (un dativo adnominal, típico del objeto de los nombres verbales), o quizás en una frase como: "Sé consejero de una buena persona, no de una mala". De las dos últimas propuestas de lectura, la primera se nos antoja más conveniente, pues resulta más general, de modo que el consejo atañe a todo el mundo y no se centra únicamente en los buenos. El planteamiento de la inclusion del pecador está más de acuerdo con la ética cristiana, aunque rodearse de buenas personas para ofrecerles consejo tampoco viola especialmente el espíritu del cristianismo. En cuanto a la posible atribución de este bloque proverbial antiguo eslavo al monóstico 704, donde los consejos se dirigen a unos destinatarios explícitos, los amigos, $\phi i ́ \lambda o r \varsigma$, también podría considerarse como origen del texto eslavo, si admitimos una omisión voluntaria o involuntaria del receptor.

¿Dónde buscar el acento monástico? Tal vez precisamente en la generalización que omite el objeto indirecto de la amistad en un ámbito de hermandad (si los eslavos arrancan del griego 704) y en la evitación de la asociación del consejero con el sofista, a través de la posible sustitución de la adjetivación del consejero por la calificación de los consejos o las personas en un contexto donde el consejero podría bien ser el abad o el prior del monasterio, СРЕЗНЕВСКИЙ (1989: s.u.) (si acaso el origen de la traducción eslava estuviese en 724).

Uno de los pilares del monaquismo hesicasta al que apuntan sutilmente las traducciones eslavas de las compilaciones proverbiales asignadas a Menandro reside en 
la imbricación de la vida y la muerte, del morirse en vida terrena, para vivir una muerte trascendente, espiritual:

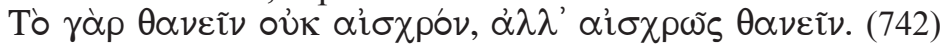

Pues no es vergonzoso morir, sino morir de manera vergonzosa.

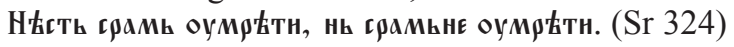

No es vergonzoso morir, sino morir vergonzosamente.

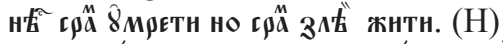

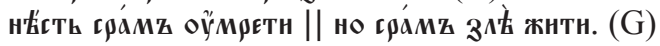

No es vergonzoso morir, sino vergonzoso (es) mal vivir.

Desde tiempos remotos, somos conscientes del concepto medieval de la "buena muerte". La bibliografía al respecto es múltiple, pero traemos a colación aquí a ARIÈS (1981), que escribe un tratado de historia social de 651 páginas en torno a las actitudes europeas hacia la muerte en el último milenio; en la cristiandad del Medioevo europeo se hace patente el sentir de que la valentía en el morir señalaba cuán buena había sido la vida de un ser humano. De esta manera, la noción de "morir vergonzosamente" quizás deja entrever que no se tiene la confianza suficiente en la recompensa eterna, lo que implica una inseguridad en torno a la vida vivida. En nuestro análisis de la lengua, caben dos alternativas con respecto a la articulación de la palabra para el universo semántico de la vergüenza, грамьнь (GIL'TEBRANDT 1882: s.u.) en Sr: грамьне-грамz не. Quizás el mejor análisis esté en la lectura adverbial, pues implicaría el verbo "ser" en afirmativo sobrentendido. La otra alternativa sería profundamente cristiana, pues genera un pensamiento místico-hesicasta que propugna la muerte ante el mundo, para el mundo: "No es vergonzoso morir, sino vergonzoso (es) no morir". Con todo, la primera interpretación es compatible con el cristianismo y con el estoicismo pagano. Los traductores responsables de los manuscritos de adscripción rusa, $\mathrm{H}$ y G, llevan la cristianización por otros derroteros más apartados del misticismo, plenos de dualismo ético, al sustituir la muerte vergonzosa por la vergüenza de una vida en pecado, obstáculo primordial para una buena muerte.

Otro de los talentos del místico le conduce a la búsqueda de la verdad en planos más trascendentes, no tan mundanos; el hesicasta cumple a rajatabla con el voto de silencio monástico para encontrar la autenticidad de las cosas fuera de las cosas:

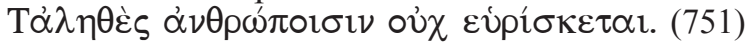

Para los hombres, la verdad no se deja encontrar.

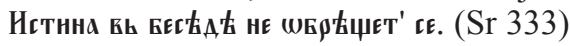

La verdad no se encuentra en la conversación.

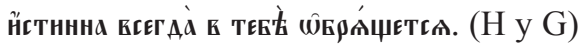

La verdad se encuentra siempre dentro de ti.

El texto griego con toda probabilidad se les antojara a los copistas eslavos demasiado pagano, sobre todo si recopilamos las palabras de Cristo: "la verdad os hará libres". De ahí parte quizás la ligera transformación del texto griego por parte del escriba serbio ( $\mathrm{Sr}$ ) en una advertencia monástica en contra de la conversación (кь Eectat) trivial. En cuanto a la redacción rusa, podemos referenciar a Lucas 17, 21, quien escribe que "el reino de los cielos está dentro de ti", para comprender la

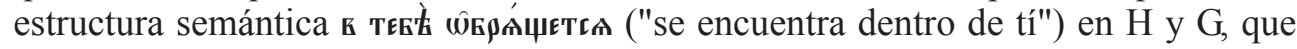
sería, no obstante, un contenido algo más socrático, no tan clarísimamente cristiano,

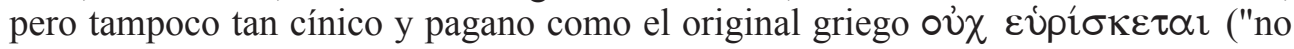


se deja encontrar"). Gramaticalmente, se da una rehelenización por la que la forma adjetival neutra plural concuerda con el verbo en singular, frente a la versión Sr que refleja una sintaxis propiamente eslava con el verbo en singular (propiciada por el hecho de que en $\mathrm{Sr}$ se ha reinterpretado el griego $\tau \dot{\alpha} \lambda \eta \theta \dot{\varepsilon} \varsigma$ como sustantivo).

Por otra parte, el análisis sintáctico también puede llevarnos a concluir que кь

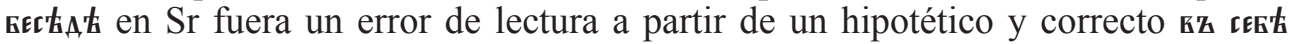
("dentro de uno"), que los escribas en H y G habrían llevado más lejos al sustituirlo por въ тевЊ ("dentro de ti") e interpolar всегда con el sempiterno propósito enfático. Además, dentro del mismo mecanismo cristianizante, se habrían librado de la negación, de manera que la verdad no sólo sí se encuentra, sino que además está dentro del interlocutor al que se dirige el monje (en lugar de dentro del monje mismo, como quizás se habría escrito en el prototipo). En cualquiera de los estadios de cristianización textual que atendamos (casual o voluntaria), en todos los manuscritos eslavos se percibe una especie de canto a la interiorización, una liberación de la materia ajena al ser humano, de la carne.

El monje que se libera de las corruptelas externas quizás alcance esa verdad crística, si puede metamorfosear en un asceta ejemplarizante, que funciona con plenitud al margen de cualquier disfrute material, vicio o placer de los sentidos físicos:

'Y $\phi$ '

El hombre sensato no se deja dominar por el placer.

Саастню смысльны не прҺльстнт' сє. (Sr 340)

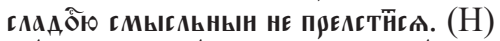

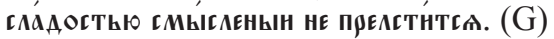

El sensato no se deja conquistar por el placer.

El punto de inflexión entre el Menandro griego y escolástico y el eslavo y monástico quizás se halle en un subtexto pagano del placer libre de mal cuando uno no se somete a él. Los traductores eslavo eclesiásticos simplemente perciben el placer como un valor negativo que conducirá al engaño. Con todo, la adaptación lingüística de las recensiones eslavas al origen griego es tan ajustada, que el matiz queda imperceptible en el texto expreso.

Tanto como la depreciación de lo material dentro del ascetismo religioso de los adaptadores monacales del Menandro griego pesa e importa la humildad como autodeprecación. Proverbios que prohíben el elogio de uno mismo o rechazan la demasía de poder a favor del valor seguramente espiritual, se gestan dentro del kenoticismo preponderante en los centros eslavos de irradiación religiosa. En efecto, la escuela ascética kenótica de la que los escribas menandreos podrían volverse herederos parciales, desaprueba fervientemente el sentimiento de superioridad en una escala social que debería uniformarnos ante Dios, es decir, arremete contra la vanagloria; de ahí que sorprendan adaptaciones eslavas que podrían contradecir hasta cierto punto el posicionamiento humilde del orante:

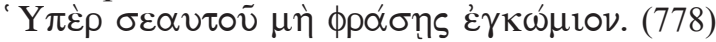

No hagas un elogio de ti mismo.

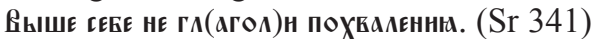

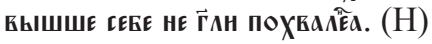




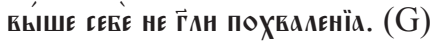

No hagas una alabanza mayor que tú ${ }^{14}$.

La preposición griega $\mathfrak{\jmath} \dot{\varepsilon} \rho$ con genitivo se atestigua en los sentidos de for, in behalf of, for the sake of; in place of; because of, about, concerning (LIDDELL y SCOTT 1996: s.u.). La misma palabra utilizada con acusativo puede significar

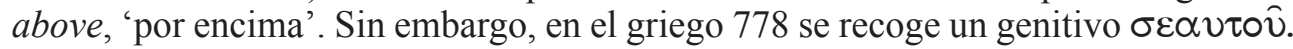
Por lo tanto, el antiguo eslavo қышш геке es una reinterpretación del sintagma preposicional griego con genitivo en una construcción con acusativo: 'más, más que tú' De aquí emana una lectura un tanto problemática desde el punto de vista ideológico: "No elogies (a nadie) más que (te) elogias a tí mismo" (extrañamente en contra de la humildad kenótica). Con todo, se puede desprender del mismo uso preposicional con rección distinta a la griega un texto como: "No elogies (a nadie) más elevado que tú" (donde la elevación se refiere al rango o posición sociales).

Así pues, una sentencia en principio hilada por el erudito griego como muestra de humildad kenótica, donde el hombre se humilla no sólo ante Dios, sino ante los miembros más bajos de la sociedad, se transfigura en los religiosos eslavos en una especie de llamamiento a la obediencia monacal no tanto inspirada por el 'kénos' (el vaciarse al mundo), como sí postulada por el 'fóbos', que se cumple siempre en las jerarquías seculares y piramidales. Además, esta humildad avanza una medida en la religión bizantina del Pantocrátor temible y abominable, donde el ser humano, al llegar a ser consciente de su lugar en el mundo, se tiene que humillar ante Dios, el emperador, el superior, el rico. Los poderosos condescienden con el patrocinio de la caridad, lo que explica el posicionamiento escribano desde una inferioridad más formularia que vívida en esta ocasión proverbial.

Pero sin duda esta manifestación de bizantinismo fóbico resulta extraña al conjunto proverbial eslavo ortodoxo. Con mayor frecuencia, los traductores eslavos monásticos se hacen eco del aspecto más externo y social de la necesidad del pobre, en su más drástica expresión entre los santos rusos. Desde la mirada de la fe kenótica, la obediencia echa raíces en la caridad o piedad. Se trata de una obligación mutua entre iguales, como San Teodosio promulga en el mandamiento cristiano "Obedeceos unos a otros" (FEDOTOV 1966 I: 392). La sumisión y el servicio al prójimo se enfatizan.

Estas contradicciones aparentes en el pensamiento pío eslavo ortodoxo, pueden entenderse a la luz de una oposición entre tendencias más moderadas o más radicales en la percepción de la riqueza o pobreza, a juzgar por el cotejo con otra literatura proverbial emanada de Bizancio (CEMEHOB 1893 y 1895). Como corrobora el Menandro eslavo, no se trata de un contraste de grado, sino de esencia en la visión religiosa subyacente. En Bizancio la modalidad piadosa severa o rigurosa echa raíces en la religión del Cristo Pantocrátor, el Juez y Rey celestial. La vertiente más moderada o dulcificada arraiga en la religión del Cristo Humillado o kenótico. Hay múltiples lugares de raigambre de las dos formas de caridad que nos reconducen al dualismo ético inseparable de la antología eslava de proverbios menandreos:

\footnotetext{
14 La ambigüedad del sintagma ви́ше сєє̇è nos lleva a ofrecer otra propuesta alternativa de traducción castellana: "No alabes a nadie más elevado que tú".
} 


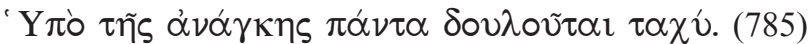

La necesidad lo subyuga todo rápidamente.

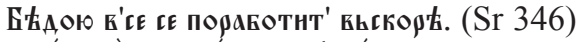

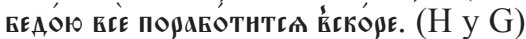

Con la necesidad todo se subyuga rápidamente.

El griego $\alpha \nu \alpha ́ \alpha \kappa \eta$ tiene un significado primario de necesidad como compulsión, lo que en Menandro se leería como el condicionamiento de que todas las cosas son esclavas de la necesidad. Secundariamente, puede significar angustia o aflicción (un estado metonímico de funesta necesidad). El eslavo EtaA refleja esta condición nefasta, pero también recoge de alguna manera el sentido primitivo de falta como pulsión o urgencia. En suma, los traductores eslavos podrían haber respetado la intención de Menandro, pues está en consonancia perfecta con la filosofia cristiana.

El ascetismo tiene raíces poliédricas en la naturaleza humana y en las necesidades religiosas de la persona (greco-eslava) que transmite a Menandro. La escisión entre el amor a Dios y el miedo de la divinidad se plasma en una bifurcación entre el asceta moderado y el radical; la deificación soterrada de la 'hibris' griega podría urgir a los recreadores eslavos del Menandro bizantino a una reconducción ideológica hacia la denuncia de la ausencia de la ley judeo-cristiana o dictarles la condena de una regulación monástica drástica:

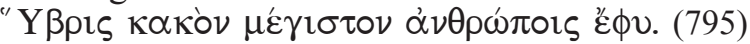

La desmesura es el mayor mal para los hombres.

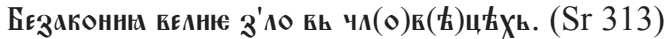

La ilegalidad es un gran mal para los seres humanos.

зако́ны мно́гїа зио ёеть в" чйцеХ. (Н у G)

Es malo (que haya) muchas leyes en los seres humanos.

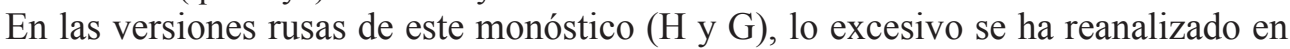
una multiplicación de las leyes emanada de un más que probable error de lectura a partir de un primigenio вєзаконнн, 'anarquía', preservado en la redacción serbia (Sr). Quizás el inicio de la palabra fuera ilegible, por lo que el escriba eslavo oriental intentó otorgar algún tipo de sentido al texto incompleto con зако́ны мно́гїа, "muchas leyes". Además notamos la omisión voluntaria del adjetivo calificativo вєкнње, 'gran', supresión derivada del reajuste textual en virtud de la comprensión del contenido. Con todo, la reelaboración de lo excesivo griego se gesta ya en la pluma del traductor eslavo meridional, pues propone un tipo general de mal comportamiento como sinónimo a la imposible e impensable 'desmesura'. Como trasfondo ideológico a este mecanismo de reelaboración, esgrimimos la fobia al politeísmo más acusada en el monje eslavo que en el erudito bizantino (más consciente de la herencia clásica).

Una cultura cristiana joven acepta sin ambages los elementos sagrados y elevados de Bizancio. Aún así, la relación inicial con el clasicismo evoluciona, y aunque en principio el acervo cultural griego se venere de manera ajena al elitismo o al oscurantismo de San Agustín con respecto a Platón y a la Antigüedad clásica en general (así por ejemplo en la concepción helénica sobre la posición dominante de la razón entre todas las facultades del alma, la inocencia aperturista (¿falta de criticismo y de conciencia real de la herencia clásica?) decae. En el periodo kievita, los libros del Paterikón se mencionan con asiduidad, y, por ejemplo, en la Vida de San Teodosio, se relata que el monje Hilarión pasa días y noches copiando libros, mientras el abad 
comercia con el gran Nicón, maestro encuadernador de libros. Estas ocupaciones llevadas con mimo encomian la regla monástica apropiada (ni insuficiente ni hiperbólica).

La prudencia de aprendiz e instructor limita y da homogeneidad al material con que los traductores antiguo rusos cuentan. Instruidos por sus propias circunstancias vitales, los monjes eslavo orientales van colmando los vacíos dejados por sus predecesores antiguo búlgaros (o vetero serbios), de los que heredan una biblioteca bizantina no tan profusa ya como las constantinopolitanas. Nos preguntamos, inspirados por DUJČEV (1978 : 229-338) о por МОШИН (1950: 32-38) hasta qué punto imaginan los responsables de los proverbios $\mathrm{H}$ y $\mathrm{G}$ (la multiplicidad legal o heterodoxia frente a ortodoxia) que los Padres en el Monte Atos carecían de la esencia mixta de los tesoros misceláneos de $\mathrm{Sr}$ (la atenuación del paganismo de lo híbrido en el rechazo de lo anárquico), donde el contenido secular trataba de silenciarse, aunque no siempre se lograse o se reconociese.

En suma, los eruditos bizantinos y los monjes (educadores de la clase alta y de la nobleza quizás) utilizaron a Menandro para revisitar distintas corrientes de pensamiento desde la perspectiva de la filosofía ética. En este sentido, me gustaría subrayar que pienso en Menandro como un constructo, un cómico, un proverbialista, un erudito griego, un religioso eslavo, un editor alemán... En este artículo, he tratado de sistematizar brevemente las líneas mayores de la instrucción (edificación) cristiana en lugares alejados del centro de irradiación cultural en Bizancio y del mundanal ruido en la Slavia Orthodoxa. Por tanto en cuanto la preocupación esencial de las escuelas filosóficas vino a centrarse en cuestiones éticas y la sabiduría moral o la frónesis (virtud individualista) se convirtió en la virtud fundamental, los gnomologios eran de gran utilidad para satisfacer metas educativas internas. Pero mientras los escolásticos y sabios bizantinos podían acceder a través de los proverbios a los grandes rasgos de pensamiento filosófico griego en Menandro y citarlo como autoridad intelectual y con propósitos eruditos, sin necesidad de una lectura más honda o explicativa, los traductores eslavos centraban todos sus esfuerzos en el pragmatismo ético, la ascésis o la unión mística.

Hasta cierto punto, se produce en el reconocimiento de este detalle una delimitación contextual para aproximarnos al Menandro eslavo y monástico con variables de concreción. En muchos casos, impera la ambivalencia ética. El elemento irónico de los originales griegos afecta a los textos eslavos en las direcciones de la polisemia y de la ambigüedad. No podemos trazar una escuela ética cohesionada a partir de los contenidos proverbiales, como tampoco una única tendencia religiosa, pero sí advertir una simbiosis de múltiples ideologías no necesariamente convergentes, incongruentes incluso.

\section{Referencias bibliográficas}

ARIÈS, P. (1981): The Hour of Our Death, Oxford University Press, Nueva York.

ABAHЕСОВ, Р. И. (1990): Словарь древнерусского языка (XI- XIV вв.). Том I-III, Русский Язык, Москва.

БУСЛАЕВ, А. (1861): Историческая христоматія иерковно-славянскаго и древне-русскаго языковъ, Учебныя Руководства для военно- учебныхъ заведеній, Москва. 
DOSTÁL, A. (1954): Studie o vidovém systému v staroslověnštině, Státní Pedagogické Nakladatelství, Praha.

DUJČEV, I. (1978): "Les rapports litteraires entre Byzance et les Slaves pendant le Haut Moyen Age", Les cultures Slaves et les Balkans, I, Izd. Bolgarskoj Akademii Nauk, Sofía, pp. 229-238.

EDMONDS, J.M (1961): The fragments of Attic Comedy after Meineke, Bergk and Kock. Volume III B. Menander, E. J. Brill, Leiden.

FEDOTOV, G. P. (1966): The Russian Religious Mind. Volumes I-II, Harvard University Press, Cambridge, Massachusets.

FRANKLIN, S. (2002): Byzantium - Rus' - Russia. Studies in the translation of Christian Culture, Ashgate/Variorum, Aldershot, Hampshire, Burlington Vt..

FÜHRER, R. (1982): Zur Slavischen Übersetzung der Menandersentenzen, Hain, Königstein.

GIL'TEBRANDT, P.A. (1882-1885): Spravocnyj i ob"jasnitel'nyj slovar' k Novomu Zavetu, I-VI, SPb (reprint, München 1988-1989, a cura di H.Keipert e F.V.Mares).

GONZÁLEZ ALMARCHA, P. (2011): La incorporación de los proverbios de Menandro a la tradición cultural eslava medieval. Tesis doctoral dirigida por los Dres. Álvarez Pedrosa y Collins, Colección digital de la UCM: (http://eprints.ucm.es/).

GORSKIJ, A., K. NEVOSTRUEV (1964a): Opisanie Slavjanskich Rukopisej Moskovskoj Sinodal'noj Biblioteki. I. Otto Harrasowitz-Wiesbaden, Unveränderter Nachdruck.

GORSKIJ, A., K. NEVOSTRUEV (1964b): Opisanie Slavjanskich Rukopisej Moskovskoj Sinodal'noj Biblioteki. III. Otto Harrasowitz-Wiesbaden, Unveränderter Nachdruck.

ИСТРИНъ, В. М. (1922): Хроника Георгія Амартола въ древнемъ славянорусскомъ nеревод $\boldsymbol{k}$, Изданіе Русскаго языка и словесности Россіской Академіи Наукъ, Петроградъ.

JAGIĆ, V. (1892a): "Разум и философија из српских кньжевних старина", Споменик XIII, Српска Кральевска Академија, Belgrado, pp.1-19.

JAGIĆ, V. (1892b): "Die Menandersentenzen in der altkirchenslavischen Übersetzung", SAWW 126, Abh. VII, Viena, pp. 1-103.

JÄKEL, S. (1964): Menandri Sententiae: Comparatio Menandri et Philistionis, Teubner, Leipzig.

КАРСКИЙ, Е. Ф. (1928): Славянская кирилловская палеография, Издательство Академии Наук СССР, Ленинград.

KRIKMANN, A. (1974): Some additional aspects of semantic indefiniteness of proverbs. Remarks on proverb semantics 2, Academy of the Estonian SSR Institute of Language and Literature, Preprint KKI-2, Tallin.

LAMPE, G.W.H. (1968): A Patristic Greek Lexicon, Clarendon Press, Oxford.

LIDDELL, H. G., R. SCOTT (1996): A Greek-English Lexicon, Based on the German Work of Francis Passow, by Henry George Liddell and Robert Scott. With Corrections and Additions and the Insertion in Alphabetical Order of the Proper Names Occurring in the Principal Greek Authors By Henry Drisler, Oxford University Press, Nueva York.

LUNT, H.G. (1974): Old Church Slavonic Grammar, Harvard University-Mouton-The Hague, Paris.

MARIÑO, R.M., F. GARCÍA ROMERO (1999): Proverbios griegos. Menandro, Sentencias, Gredos, Madrid. 
МЕЩЕРСКИЙ, Н. А. (1978): Источники и состав древней славянорусской переводной письмености $I X-X V$ веков, Издательство Ленинграского университета, Ленинград.

MIKLOSICH, F. (1886): Radices linguae Slovenicae veteris dialecti, Lipsiae in libraria Weidmannia.

MORANI, M. (1996): La traduzione slava delle gnomai di Menandro, Edizioni dell'Orso, Alejandría.

МОШИН, В. (1950): "Русские на Афоне и русско-византийские отношения в XI-XII вв", Byzantinoslavica, 11, 32-38.

CEMEHOB, В. (1892): Мудрость Менандра по русскимъ спискамъ, еn Памятники древней писменности. LXXXVIII, Типография Императорской Академіи Наукъ, Спб, 1-42.

CЕМЕНОВ, В. (1893) : "Греческий источникъ “изреченій исихія”", Журналь Мнистерства Народнаго Просвтщенія. Шестое Десятильтіе. Часть CCLXXXVIII. Типографія В. С. Балашева и Ко. С., Петербургъ.

CEMEHОВ, В. (1895): "Пчела въ 44 главы", Чтенія въ Императорскомъ Обществъ Исторіи и Древностей Россійскихъ при Мовсковскомъ Университет к. Книга вторая. 173, Москва.

СЛАВЯНСКАЯ БИБЛИЯ ДЛЯ WINDOWS (2002): Набор производился по стандартному "елизабетинскому" изданию 1900-го года, Донецк.

СПЕРАНСКІЙ, М. Н. (1898): "Разумфнія единосторочыя Григорія Богослова и Разуми мудраго Менандра въ русскомъ переводњ", Извъстія. Отдћленія русскаго языка и словености россійской академіи наукъ. 1898. Тома III- го. Книжка 2-я, Санктпетербургъ.

СРЕЗНЕВСКИЙ, И. И. (1989): Словарь древнерусского языка в трех томах, Книга, Москва.

THOMSON, F. J. (1999): The Reception of Byzantine Culture in Mediaeval Russia, Ashgate Collected Studies CS590, Aldershot, Inglaterra.

TOY, C.H. (1908): A critical and exegetical commentary on The Book of Proverbs, T. and T. Clark, Edinburgh.

VEČERKA, R. (1961): Syntax aktivních participií v staroslověnštině, Státní pedagogické nakl., Praha.

ЦЕЙТЛИН, Р. М. (1999): Старославянский Словарь (по рукописям Х-ХI веков), Русский язык, Москва.

WIERZBICKA, A (1997). Understanding Cultures Through Their Key Words: English, Russian, Polish, German and Japanese, Oxford University Press, Nueva York. 